\title{
Post-failure fatigue behaviour of intact sandstone from burst prone coal mine in Ostrava-Karvina coalfield
}

\author{
MN Bagde \\ CSIR-Central Institute of Mining \& Fuel Research, \\ Nagpur, INDIA \\ mnbagde@cimfr.res.in
}

\begin{abstract}
In the literature, mostly, pre-failure behaviour of the intact rock in static and rarely in cyclic loading is reported. In various earlier publications on the subject by the authors, pre-failure fatigue behaviour of intact rock is discussed. The post-failure behaviour of the intact rock in the laboratory is still a topic of hard discussion and of debate. Many researcher's of the opinion that post-failure behaviour of the intact rock is not of that rock under testing but it is simply of servo-controlled testing machines. However, in the present paper, post-failure fatigue behaviour of intact sandstone rock obtained from the rock burst prone coal mines in OstravaKarvina region in the Czech Republic subjected to uni-axial cyclical loading is discussed. From the presented results, the importance of post-failure behaviour in mine pillar and support design is emphasized. This study has practical significance to the behaviour of rock and rock masses within the excavation systems subjected to dynamic cyclic loads, since tested rocks were from the rock burst prone coal mines from the Ostrava-Karvina Coal Basin in the Czech Republic.
\end{abstract}

Keywords-post-failure fatigue behaviour; carbiniferrous rocks; Ostrava-Karvina coal basin; uni-axial cyclic loading, pillar design.

\section{INTRODUCTION}

Pillar stability along with support requirement in coal as well as in hard rock mines is a subject of interest since long. Over the years quite notable research is being carried out and reported in the literature. The ultimate aim of all these research studies is to achieve safe mining environment with better ground control. It also helps with improved production and productivity with improved safety of the men and machineries implied in mining excavation practices. Safety in mines all over the world till today is of a great concern despite of all these good efforts. Due to deeper mines and complex geological structure, pillar stability is of a great concern since pillar failures are being frequently reported all over the world even after good developments in modern support system.

In India also, few cases of major roof fall in longwall, bord and pillar coal mining roadways and depillaring faces are reported [1, 2]. Reference [1] have cited the field experience of already extracted longwall panels at the Balrampur mine of SECL where a fall of considerable extent is reported when the longwall face is advanced to 67 $\mathrm{m}$. This loading caused extensive damage to the powered supports installed at the face and subsidence is observed on the surface. Reference [2] has cited the depillaring of the seam induced roof failure at roadway junctions in the bottom section near the goaf edge during a major roof fall. In this particular case, superimposed development is made along the floor to full height extraction of a thick coal seam in a single lift by the blasting gallery (BG) method. According to him, the presence of strong and massive overlying roof strata caused high mining induced stress over the pillars facing the goaf line during the depillaring and ultimately, the pillar extraction caused collapse ahead of the face. From the above cited few failed cases, it seems pillar design and its stability during actual mining is a complicated issue and also paramount subject in mining related to the safety, rock mechanics and ground control point of view. Since, in an underground pillar design, determining actual stress acting over the pillars is a very difficult task.

At the present, mostly, tributary area theory, numerical modelling and neural networks methods combined with other empirical and mathematical approaches are being generally used to determine pillar stress. Recently, [3] studied the stress-strain behaviour of coal pillars using a three-dimensional finite element based numerical study. Besides the numerical modelling, statistical and analytical methods, the probabilistic methods, rock mass classification approaches and artificial intelligence based or their hybrids methods have been applied successfully in designing pillars in the case of coal or hard rock mines. Also [4] recently investigated the suitability of different supervised learning (SL) algorithms for the prediction of pillar stability (PS) in underground engineering. They have considered total of 251 pillar cases between 1972 and 2011 including stable and failed one available from the reported data sources in their study. The main objective of their study was to compare different classification techniques for PS detection in hard rock mines. Mainly six data features were used in their analysis namely: pillar width, pillar height, the ratio of pillar width to its height, uni-axial compressive strength of the rock, pillar strength and pillar stress. Mine structures are subjected to non-uniform stress distribution, some in prefailure condition, others in post-failure condition, and some 
in both [5]. Therefore, according to him, modelling mine structure stability must consider the complete stress-strain curve of individual rock materials. He is of the firm view that ground control deals with structures mostly in the postfailure region and there is the need of the further advanced research in this area.

Over the years, various researchers from their own field experiences, obtained instrumentation data from the field during actual mining operation, from the laboratory testing in static, quasi-static as well as dynamic/cyclic testing with different strain rates, even post-peak failure behaviour studies in the laboratory as well as in-situ including other methods tried to provide pillar design concepts and ideas. With the help of all these research tools, various empirical approaches by different researchers have been proposed for pillar design and been applied in practice according to their suitability and as per the individual convenience. More often than not, these methods are questionable because pillar failures did occur even though the failed pillars had been considered stable i.e. safety factor $(\mathrm{SF})>1$ [4]. According to them, empirical methods are based on interpretation of available data source and it is therefore difficult to generalise the obtained results beyond the scope of the original site characteristics. Keeping this in view, a long back particularly for Indian coal mining conditions, Sheorey and his research team [6-11] came out with Indian Coal Mining RMR. Also, suggested empirical formula's to design pillar and support requirement. They have included large numbers of stable as well as failed cases of coal mining pillar from India to develop pillar strength estimation empirical formulae which is being used largely not only in India but elsewhere too.

Based on the studies conducted by the author itself on rock burst prone coal measure rocks from Ostarva-Karvina coalfield in the Czech Republic in the laboratory subjected to cyclic loading in uni-axial compression and observation made have been discussed here. For more details related to testing equipment, testing scheme followed, rock types tested and data interpretation methodology followed, kindly refer to the various publications of the authors [12-16]. The experience gained through these tests and based on the available data source from the reported literature, the comparison of failure mode observed in the case of insitu pillar in mine with that post-failure behaviour in the laboratory is discussed and presented herewith. Also, the possible application of the observed post-peak failure behaviour of intact rock in the laboratory in designing the insitu mine pillar and support estimation is discussed. The basic purpose of this paper is achieving safe mining environment in the case of difficult mining conditions.

\section{POST-PEAK BEHAVIOUR OF ROCK}

With the development of stiff testing machines in the

1960 s and 1970 s, it is now possible to obtain information about the post-peak failure state parameters of rocks especially highly brittle in nature. Rock testing with these testing machines enable us the complete stress-strain curves under compression. Now, it is possible us to process and use the previously unknown information on the behaviour of rocks under compression at the post-peak failure state [17].

For some rock engineering problems, properties related to the post-peak state part of the stress-strain behaviour are important. While, comparing the case of in situ with that in the lab testing [18] of the opinion that the high stresses that can lead to the material entering the post-peak region either occur directly, as a result of excavation, or indirectly at the corners and edges of rock blocks which have been disturbed by the process of excavation. While, [19] emphasised the need towards estimation of the strength and deformability characteristics of rock masses for the analysis of underground excavations. The formation of plastic or postfailure state regions around underground structures is sometimes unavoidable; design procedures and supporting systems are then to be modified considering the existence of these regions. In mining applications, the safe and optimum design of supporting pillars is not only based on the peak pillar strength, but also on the post-failure behaviour, particularly in coal mining and the mining of valuable ores in deep underground mines. Parameters related to the postfailure portion of the complete stress-strain behaviour play a major role in such design efforts [17]. The best approach for the estimation of parameters related to the post-failure part of the stress-strain behaviour of supporting pillar elements is to conduct large-scale in-situ compression tests on such pillars [3].

The brittle fracture of rocks is the most studied process in rock mechanics, and in particular, the post-peak behaviour of rocks is one of the key issues in rock mechanics. The complete stress-strain curves for various rocks using a stiff testing machine was first obtained successfully [20] and classified rock mechanical behaviour under uni-axial compression in to Class I and Class II. As shown in Fig. 1, for Class I behaviour, axial strain remains stable even though the axial stress exceeds the peak strength, and the stress-strain curve monotonically increases in axial strain. On the other hand, for Class II behaviour, the rock deformation suddenly becomes uncontrolled when the axial stress exceeds the peak strength, and the curve does not monotonically increase in axial strain. Recently, servocontrolled testing machines are commonly used, and various experimental values have been selected as the feedback signal. For more detailed literature on the subject, kindly refer to [21] recent publication. Aadditionally, very good articles and first of its kind on the subject related to the postpeak behaviour studies on rock includes [20] and [22] including others [23-24] on the subject matter. The recently developed servo-controlled testing machines and various other kind of testing methods available permit the failure behaviour of rock in detail in pre- and post-peak region. However, at the present, there are still difficulties to obtain complete stress-strain curve of brittle rocks in laboratory experiments, and Class II post-peak behaviour has not been sufficiently clarified. Also, there is still controversy surrounding post-peak failure behaviour of the rock in the laboratory. Some of the researcher's are of the opinion that post-peak behaviour of the intact rock in the laboratory is not an intrinsic material property but it is related to the 
machine behaviour. However, it is seen that post-peak behaviour of the intact rock does give some sort of indication the rock will behave after attaining peak strength or failure and have been applied successfully by various researchers in defining failure behaviour of the intact rock from the laboratory testing. Few of these notable studies also tried to apply their findings to the field problems mainly insitu pillar behaviour in coal and hard rock mines, understanding rock burst problems in coal and hard rock mines and their mitigation, and determination of in-situ stress including other applications related to the strata control and rock mechanics.

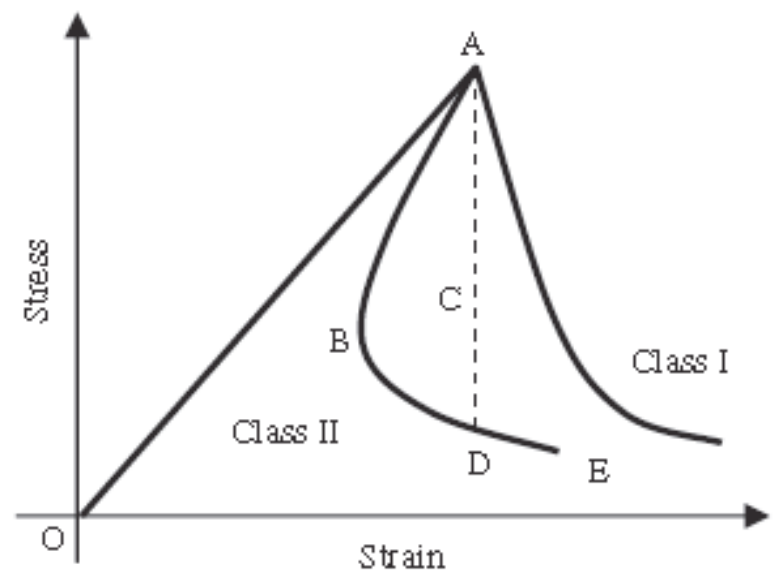

Fig. 1. Representative figure for stress-strain curves of Class I and Class II behaviour of rock failure under uniaxial compression [21].

Understanding the dynamic material responses of rocks is critical in a variety of rock engineering and geophysical applications (underground excavation, quarrying, drilling, bumps, rock-bursts, seismic events, rock blasts, rock crushing, earthquakes, projectile penetration etc). However, as yet no recommended methods have been suggested by the International Society of Rock Mechanics (ISRM) to provide guidance for dynamic tests. The dynamic testing results obtained with different method and instrumentation are so scattered that cross-referencing of others' results is almost impossible [25]. According to him, thus, it is necessary for the rock mechanics community to develop reliable dynamic testing methods. To test the dynamic mechanical properties or post-failure behaviour of rocks, one needs a reliable testing device. For testing rocks under high strain rates from $10^{2}$ to $10^{3} \mathrm{~s}^{-1}$, the Split Hopkinson Pressure Bar (SHPB) is an ideal choice. Unlike ductile metals, brittle materials have small failure strains $(<0.2 \%)$ and hence, if the loading is too fast, as in conventional SHPB test, the specimen may fail in a non-uniform manner. To achieve accurate measurements in SHPB tests, one has to make sure that the specimen is experiencing an approximately equilibrium stress state (dynamic stress equilibrium or dynamic force balance). Because it takes 3-4 rounds for the stress wave travelling in the specimen to achieve such an equilibrium state, the dynamic loading should be slow and of appropriately long duration. The pulse shaping technique was proposed to slow down the loading rate and thus to minimise the so-called inertial effect associated with the stress wave loading [25].
The 3-S method (Special Shaped Striker), including the half-sine wave conception, special shape striker design, test applications is introduced by [26]. They have improved SHPB for conducting rock mechanics research serving deep underground projects. From the reported literature, it is found that for rock material, its dynamic strength increases with strain rate following an exponential law. The static strength of rock with a strain rate of $10^{-5}-10^{-2} \mathrm{~s}^{-1}$ can be obtained with hydro-servo controlled machines. For rock tests with loading rates of $10^{-2}-10^{\circ} / \mathrm{s}$, various pneumatic driven machines were invented [27]. For higher strain rates exceeding $10^{3} / \mathrm{s}$, gas guns have been successfully deployed to measure the response of rocks. However, for an intermediate loading rate of $10^{0}-10^{3} / \mathrm{s}$, which is common in many rock mechanics processes, there is a scarcity of experimental equipments and available data for reference [26]. With the large diameter SHPB, the intermediate loading rate was obtained successfully. While, with the halfsine wave by the 3-S method for a large diameter SHPB, many rock experiments at intermediate loading rates were conducted and studies were reported [28].

\section{RESIDUAL STRENGTH OF INTACT ROCK}

The broken zone extension around an underground opening depends on the strength parameters of the rock. Also, the compressive strength of the rock material is an influential parameter in estimating the thickness of the broken zone (rock-load height) and support pressure is taken into account. In solving closed-form solutions for underground openings, the residual strength parameter in accordance with the post failure behaviour of the rock is considered. The extension of the broken zone relies on the residual value of the intact rock strength is also substantiated by many notable authors [29]. The effect of the compressive strength of a rock material in the form of the residual value must be included because it loses its initial value due to stress relief or an increase in the strain. A stress reduction scale is suggested by [29] as:

$$
\sigma_{\mathrm{cr}}=\mathrm{S}_{\mathrm{r}} \cdot \sigma_{\mathrm{ci}}
$$

where, $\mathrm{S}_{\mathrm{r}}$ is the strength loss parameter that quantifies the jump in strength from the intact state $\left(\sigma_{\mathrm{ci}}\right)$ to the residual condition $\left(\sigma_{\mathrm{cr}}\right)$. It explains the brittleness of the rock material: ductile, softening, or brittle. By definition, $S_{r}$ will fall within the range $0<S_{\mathrm{r}}<1$, where $\mathrm{S}_{\mathrm{r}}=1$ implies no loss of strength and the rock material is ductile, or perfectly plastic. In contrast, if $S_{\mathrm{r}}$ tends to 0 , the rock is brittle (elastic-brittle plastic) with the minimum possible value for the residual strength as highlighted in Fig. 2. As a first guess in proposed support pressure equation by [29], $\mathrm{S}_{\mathrm{r}}=1$ is taken into account for the poor and very poor rock masses with GSI $<27$ because their post-failure behaviour is perfectlyplastic. While, they have suggested for average and good quality rock masses, the exact value of the residual strength for the intact rock can be determined from stress-strain response of the rock in the laboratory tests. However, again conducting and obtaining such complicated tests is costly and time consuming affair. Also, such testing facility is not 
so easily available in most of the research and educational technical institution yet, and then leaves aside mining companies or operator's.

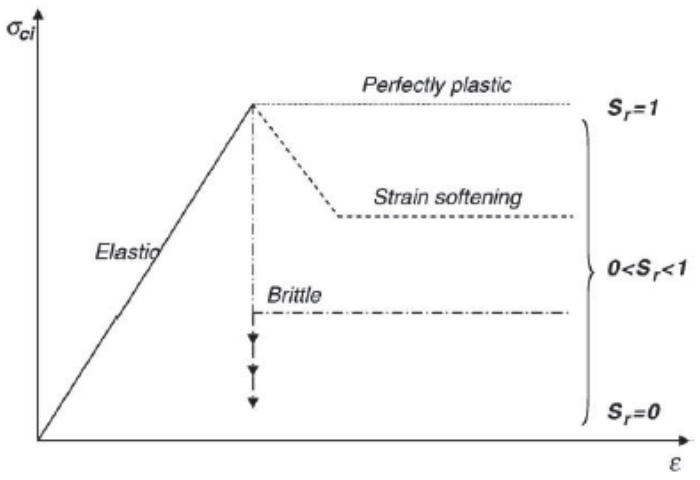

Fig. 2. Different post-peak strength models of rocks [29]

\section{APPLICATION OF POST-PEAK BEHAVIOUR OF THE ROCK}

Knowledge of the post-failure behaviour of pillars is becoming more important as the depth of mines increasing. The mine design process must include calculations of pillar failure, but the post-failure stress-strain relationship is often unknown. [30] has described the post failure stress-strain relationship for rock fill-confined pillars in the Buick Mine with estimation of rock mass modulus, uniaxial compressive strength, and residual strength etc. They have used data from the calibrated model to show a strain-hardening stressversus-strain relationship. This knowledge is very critical for the design of mines that uses partially failed pillars to carry overburden load. In Fig. 3, view of a pillar that had undergone severe scaling over time is shown. The original pillar edges can still be seen in the marks on the roof.

According to [31], because these pillars tend to be small by virtue of the shallow depth, there are limited options when designing the sequence of cuts and also the sizes of the remnants (snooks) that are to be left in situ. Snooks very often have to be left as protection during the actual process of mining a pillar. They, therefore, have to be large enough to remain stable while there are still unmined pillars close to them, but they have to be small enough to fail once mining has progressed i. e. depillaring in the case of bord and pillar coal mining and or retreat mining with caving. Fig. 4 shows the failure took place of the intact sandstone rock speci

men in the laboratory subjected to uni-axial cyclic loading. The typical failure pattern observed at high loading frequencies, suggests that this type of failure might continue to support an increase in the load until its final failure. According to [32], some lateral restraint stress might develop at the machine-specimen boundary due to different deformations between the steel loading platen and the specimen in uni-axial compression testing.

The crack pattern (failure mode) of compressive specimens is influenced by this lateral restrain stress because it results in tri-axial compressive stress states at the end regions, which may delay orprevent strain localization

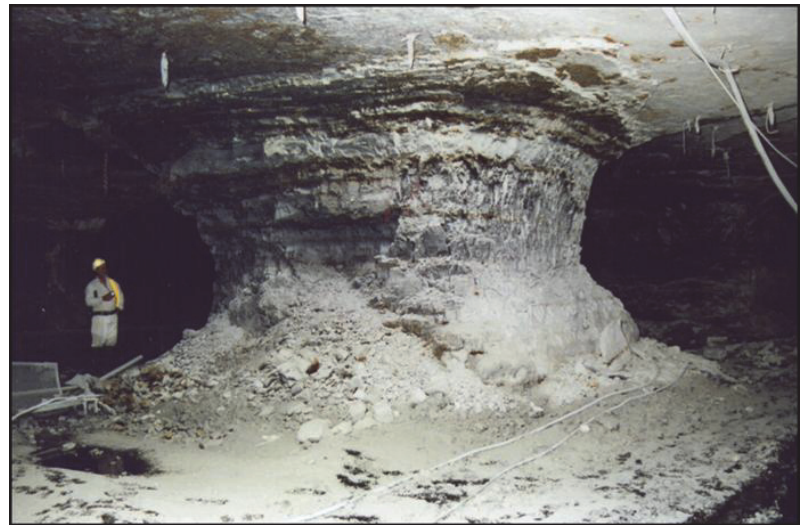

Fig. 3. View of a pillar that had undergone severe scaling over time. The original pillar edges can still be seen in the marks on the roof. If scaling had not taken place, the person in the background would have been inside the pillar [31]

and formation of macro cracks. Therefore, when plain steel loading platens are used for testing for a short specimen, an hour-glass-type failure as shown in Fig. 4 is usually obtained (not necessarily always). According to their findings [32] on concrete they were of the opinion that this type of failure mode cannot be used to characterize compressive failure of concrete. In simple terms in uni-axial compressive testing such type of failure mode is unacceptable and will not help to characterise the behaviour of the material. However, in coal mines such type of failure in insitu coal pillars are mostly observed when subjected to severe dynamic loading in the case of depillaring and or retreat mining with caving. It is also highly welcomed or accepted one since it will take care of load coming and will not fail violently or abruptly causing damage to the men and machinery at work. It will also provide sufficient indication and time gap and one can continue to work upon until situation permits. In such cases, typical stress-strain curve as shown in Fig. 5 is obtained in the laboratory testing on the rocks. Another reason for the strength increase with loading frequency in this case might be that the load increases so rapidly that there is no time for flaws or cracks to nucleate or propagate. These type of post-peak failure behaviour showing residual strength of the rock is corresponds to Class I behaviour as explained earlier in Fig. 1. In this type of rock behaviour the value of $S_{r}$ is suggested at 1 to be used in equation (1) as provided by [29].

Sometimes, the presence of strong and massive overlying roof strata generate high mining induced stress over the pillars facing the goaf line during depillaring. If such situation arises, on many occasions the pillar extraction has caused collapse behind the face line in the case of retreat mining called as "over-riding". This situation is unwarranted in mining environment; since good quality coal or ore is lost and even sometimes men and machineries are get trapped causing significant financial losses to the operators. And even on few occasions mining needs to be suspended in such area which will again loose whole panel/stope with blocked coal/ore to be extracted. This will again raise the serious issue of safety and health hazard due to the proneness to fire and or spontaneous heating in the 
case of coal and subsequently causing subsidence on the surface.

As shown in Fig. 6, shear and violent failure is observed in siltstone rock specimen when subjected to cyclic uniaxial loading in the laboratory. It is also observed on few occasions that broken pieces of the failed specimen are thrown out of the specimen basement at high speed and energy. This type of failure suggests sudden, violent and brittle type of failure of the rock specimen. Such rock types when subjected to severe loading condition in in-situ expected to fail abruptly, suddenly and violently without giving any indication and time to retreat, causing much damage to the mine workings, men and machinery. In the laboratory, when such rocks are tested in servo-controlled testing machine failed to produce post-peak behaviour of the rock after its failure as shown in Fig. 7. Typical stress-strain curve showing sudden and violent failure (Class II behaviour) with no residual strength of sandstone rock subjected to uniaxial cyclical loading is shown in this figure.

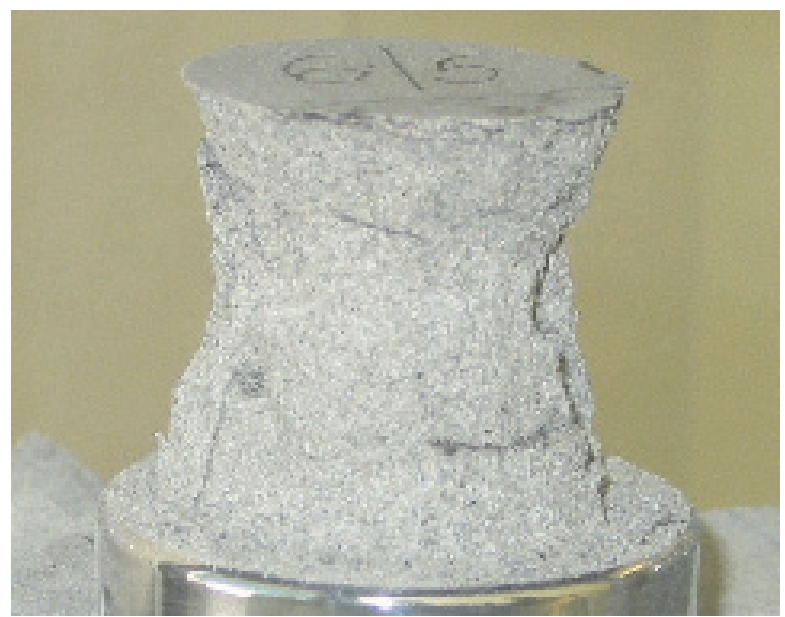

Fig. 4. Typical failure observed in sandstone rock specimen $(\mathrm{f}=20 \mathrm{~Hz}$, $\mathrm{A}=0.05 \mathrm{~mm})$

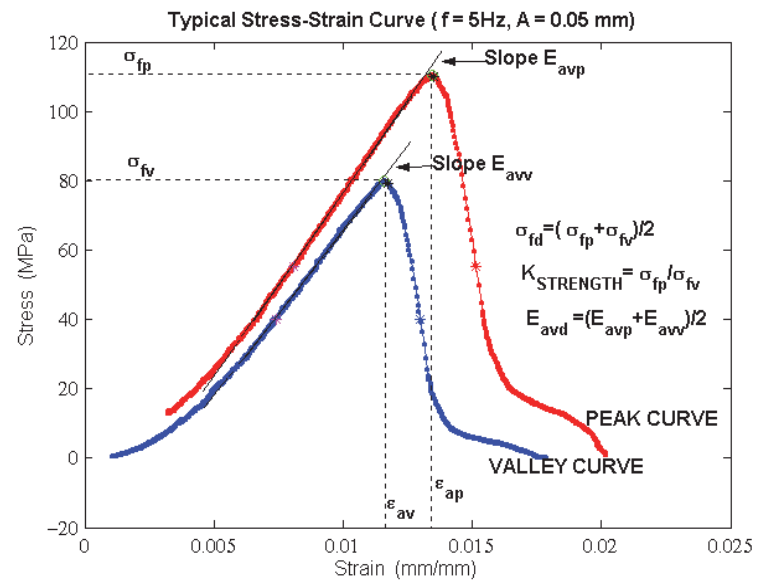

Fig. 5. Typical stress-strain curve for sandstone rock specimen with postpeak behaviour $\left(\mathrm{f}=5 \mathrm{~Hz}, \mathrm{~A}=0.05 \mathrm{~mm}, \sigma_{\mathrm{ci}}=110 \mathrm{MPa}, \mathrm{S}_{\mathrm{r}}=1, \sigma_{\mathrm{cr}}=110 \mathrm{MPa}\right)$

This type of rock failure suggests Class II behaviour as explained earlier in Fig. 1. Though in this case obtained uniaxial compressive strength is at around $130 \mathrm{MPa}$ and at higher side when compared to $110 \mathrm{MPa}$ as shown in Fig. 5, however, failed in violent mode with no residual strength and since $S_{\mathrm{r}}$ value should be considered at 0 or $<0.5$ to be used in equation (1) as provided by [29]. If we use simply uni-axial compressive strength in RMR or pillar strength formulae's, then, it will overestimate the RMR value and pillar strength and thus will under-estimate the support requirement as well as overestimate safety factor in the case of pillar designing. Since, estimated support may be probably insufficient and may lead to the catastrophic failure in such type of rocks. One should be careful while dealing with this type of rocks and due consideration should be given to post-peak behaviour of the rock in such cases, while designing initially pillar or support estimation etc.

It shall be noted here that rock-bursts are common to underground mines, particularly those operating at a deeper depth with brittle rock environment. A practical definition of rock-burst is that it is a violent and sudden failure of a finite rock mass volume into an underground excavation; such failure is violent enough to hamper mining activity and it registers as a seismic event. Rock-bursts are usually associated with more brittle rocks types, regionally scaled planes of weakness, and high stress concentration. The distribution of stresses, properties, and structure of the rock mass are important information for the determination of the process leading to rock-burst. Strain-bursts are considered to be one of three types of rock-burst phenomena, the others being mine pillar bursts and fault-slip bursts [33]. The strain-burst mechanism is primarily caused by high-stress concentration at the edge of a mine opening. Pre-cursor events occur as small slivers of forcefully ejected rock to complete wall fragmentation and displacement imposed to developments drifts, stopes, and shaft floors during shaft sinking. Thin plates break off roughly parallel to, and following the curvature of the free face. Although strainbursts occur in massive, relatively continuous rock, jointed rock could also suffer from the imposition of high stresses hence causing spalling features at the surface.

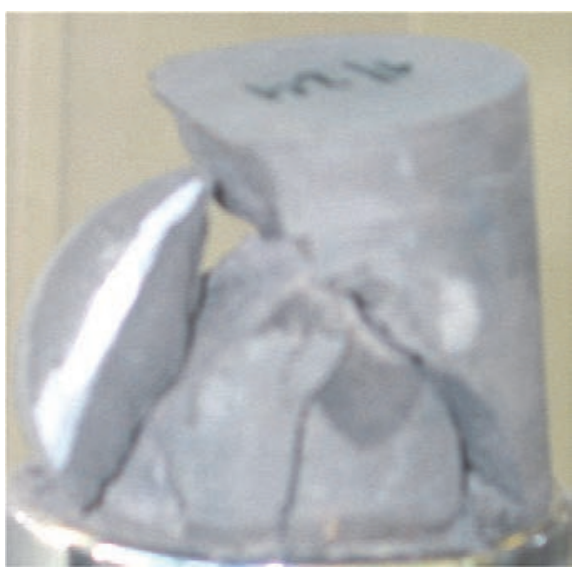

Fig. 6. Shear and violent failure observed in siltstone rock specimen in cyclic loading in the laboratory $(\mathrm{C} 1 / 24-0.1 \mathrm{~Hz}-0.1 \mathrm{~mm})$

Strain-bursts in brittle rock are common to deep underground mines. The state of stress at the boundary 
of mine openings is dictated by a biaxial stress/loading condition. [34] have reported the series of results of biaxial compression tests carried out on $100 \mathrm{~mm}$ cubic norite rock samples, under different horizontal-tovertical stress ratios. According to their findings, the biaxial compressive strength is considerably higher than the uni-axial one. It is also found that the norite sample

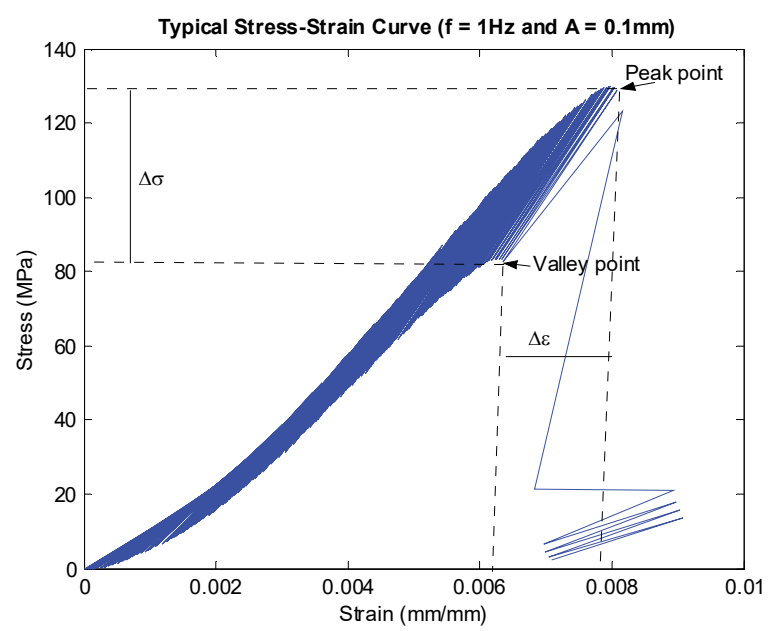

Fig. 7. Typical stress-strain curve showing sudden and violent failure (Class II behaviour) with no residual strength of sandstone rock subjected to uniaxial cyclical loading $\left(\mathrm{f}=1 \mathrm{~Hz}, \mathrm{~A}=0.1 \mathrm{~mm}, \sigma_{\mathrm{ci}}=130 \mathrm{MPa}, \mathrm{S}_{\mathrm{r}}=0\right.$ or $<0.5$, since $\sigma_{\mathrm{cr}}=65 \mathrm{MPa}$ when considered $\mathrm{S}_{\mathrm{r}}=0.5$ )

behaviour under biaxial loading mirrors field behaviour where shearing and progressive spalling of the boundary are observed prior to strain-bursting. The failure is initiated by rock spalling at the sample free faces i. e. in the plane of biaxial loading. Ultimately, it is the outof-plane shear failure mechanism that causes the sample to collapse. Shear failure takes place violently and abruptly and is accompanied by considerable audible noise. As shown in Fig. 6 and 7, failures observed were in shear and violent type. And thus suggest rock prone to the rock-burst and brittle type failure and one need to be careful while dealing with such types of rock.

\section{DISCUSSION}

According to [5], failure initiation in rock strata around mine structures does not necessarily lead to final collapse. $\mathrm{He}$ is of the view that in most of the cases, failures or fractures either stabilize after the initial failure or propagate over time before the final collapse. Frequently, the failure or fracture stops after propagation for some length of time or distance. Also, he has put two queries forward to the rock mechanics community: How can we tell the difference between a stable failure and an unstable one? Are there stable shapes of roof fall cavity or gob caving?. Answer to these questions is lies in his own concluding remarks: Despite the great progress of the last three decades, further research, especially in the fundamental aspect, is absolutely necessary in nearly every subject area if ground control is to continue solving the problems of daily mining operations.
From the laboratory studies related to failure it is said that the process of fracture and failure involves crack initiation or extension of pre-existing cracks and their propagation. At first a stable propagation takes place, which in the presence of continuing load, changes to unstable fracture propagation and finally, to failure (see Fig. 8). The third stage of stress-strain diagram consists of a non-linear elasto-plastic relationship. Strain hardening takes place in this range. Slope of the line is decreases continuously, and the seismic activity is increases exponentially until failure. The overall fracture and failure is said to be brittle when a significantly low level strain is developed until the ultimate stress with little or no plasticity. Ductile failure is associated with considerable amount of plasticity between yield stress and ultimate stress. The example of dynamic energy phenomena due to micro-cracks, heat generated or due to strain hardening is shown in Fig. 8. From the figure, it can be observed that energy is recovered once the micro-cracks are closed and it suggests that rock has a memory, as already reported through acoustic emission studies. Also, it supports the proposition made by [5] as stated in the above regarding failure initiation observed in rock strata.

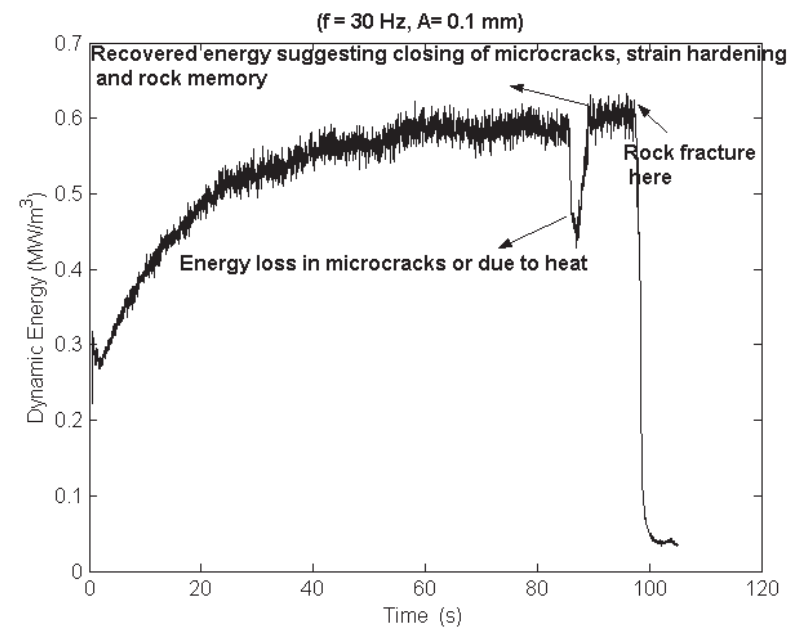

Fig. 8. Dynamic energy vs. Time plot illustrating energy loss phenomena [15]

The breakage energy associated with any comminution process can be explained by two approaches: stress or energy based. The stress approach is used to explain the strength of the rock or material on macroscopic scale such as compressive, shear or tensile strength. The fracture or the strength depends on many factors, such as macro- and micro-structure of the material, amplitude and rate of stress, and the method of stress application. Due to an inability to uniquely quantify the strength of a heterogeneous and anisotropic material, stress and energy criteria are often lumped together [33].

The energy approach is also a macroscopic scale of representing fracture strength but it takes into account the crack size present in the material (the Griffith theory). With the knowledge of the strain energy (energy absorbed under stress application) and the surface energy (workdone in creating unit surface area), the minimum work required in a 
comminution process can be estimated. Alternately, if the actual energy used is measured, one can estimate how efficiently it is used. According to [36], an alternative to stress-strain approach is to consider under what compressive stresses cracking occurs. According to them, Griffith introduced the concept that local tensile stresses could exist in a material subjected to all round compression if the material contained flaws. Intact rocks contain numerous flaws, e. g. grain boundaries, cleavage, vugs, and microcracks, hence should develop "Griffith" cracks if subjected to sufficient concentrations. From their study [37] on dynamic fatigue properties of the cracked, frozen samples under different loading cycle frequencies have noticed that the failure process of the rock depends mainly on the extension, coalescence, nucleation of the intrinsic flaws and cracks, and the consequential formation of the main macroscopic cracks. According to [38] micro-fracturing is the principle mechanism of fatigue failure. According to [39], the testing facility in the given time works in the mode of constant energy input into the specimens. Thus, the intermediate drop (as shown in Fig. 8) in mechanical output means that energy must have been involved there. According to him, this energy is probably the heat energy. At this time, the resistance of the test specimen is concentrated on the formed shear plane, friction develops on this surface and this friction energy converts into heat.

The peak strength of a sample is a function of the boundary conditions of the test, and hence, not an inherent material property [22]. According to [32], the maximum stress depends not only on the material property but also on the structural geometry and boundary conditions, and hence, the strength failure criterion in terms of the nominal stress is not suitable for a structure made with a brittle material. They were of the opinion that the failure process for a brittle material could be described by the elastic energy dissipated in the structure. Since only the elastic energy is involved, a single energy criterion is enough to describe the failure of structures made of brittle materials. According to [40], the strain energy release rate is one of the most important parameters, with regard to fracture, and is defined as the amount of energy release per unit increase in crack surface area.

Citing various sources, [41] noted that unstable deformation or rupture of rocks occur whenever the amount of energy required for continued deformation is less than that released as a result of the deformation. The excess energy leads to dynamic rupture, which is accompanied by the radiation of acoustic and seismic energy from the source of the instability and might, in some cases, results in flying fragments. This type of instability can occur in large- scale (earthquake, rock bursts) or in small scale rupture events. And it is necessary to identify such type of rocks, so that in initial designing of pillar or support system due consideration should be given. Post-failure behaviour of the rock is certainly helps in identifying this type of rocks.

As a first step, in proposed approach on the residual strength of the rock based on the post-failure behaviour, it is suggested to replace compressive strength with residual compressive strength in Indian Coal Mining RMR and pillar designing empirical formulae's. As suggested by [29] stress reduction scale may be considered as given in equation (1). The value of $S_{r}=1$ may be taken into account for the poor and very poor rock masses with $\mathrm{RMR}<40$, because their post-failure behaviour is assumed to be perfectly-plastic. For average and good quality rock masses, on the other hand, the exact value of the residual strength for the intact rock can be determined from stress-strain response of rock in the laboratory tests, so the value of $S_{r}$ can readily be obtained.

\section{CONCLUSIONS}

After almost more than 25 years of use throughout the India in coal mining, the record of Indian Coal Mining RMR systems as well as empirical formulae's proposed to design pillar strength and support estimation in geological and engineering practice speaks for itself. This system have become entrenched as the most effective empirical design tools for determination of rock mass quality, estimating rock mass properties, pillar strength and mining support measures etc. However, it is prudent to use to apply this classification in the letter and spirit for which they were developed, and to learn from corroborative case histories. In the present paper, an approach based on post-peak behaviour of the rock to be considered while designing mine pillar and or support system is presented. On the line of [29] stress reduction scale is suggested and same shall be replaced with uni-axial compressive strength used presently in Indian Coal Mining RMR. It is expected that application of the proposed approach will certainly help in the better spirit of mining industry in achieving cent percent safety in mine working environment.

Let us conclude with this applicable wisdom: "It is not the things you don't know that get you into troubles. It is the things you think you know for sure." (Attributed to Sir Winston Churchill). "When you can measure what you are speaking about, and express it in numbers, you know something about it, but when you cannot express it in numbers, your knowledge is of a meagre and unsatisfactory kind.” Lord Kelvin (1824-1907) (re-quoted from [42]).

\section{ACKNOWLEDGMENT}

The presented work forms part of the doctoral thesis of the author. Laboratory tests were carried out at the Department of Mining Engineering and Safety, Faculty of Mining Engineering and Geology, VSB-TU, Ostrava, Czech Republic. Author wish to thank Prof. V. Petros for his able guidance during the studies. Thanks are also due to Director, CSIR-CIMFR for his kind permission to publish this paper. The views expressed therein are of the author and not necessarily of the Institute he belongs to.

\section{REFERENCES}

[1] A.Kushwaha and G.Banerjee, Exploitation of developed coal pillars by shortwall mining - a case example, Int J Rock Mech \& Min Sci, vol. 42, pp. 127-138, 2005 . 
[2] R. Singh, Staggered development of a thick coal seam for full height working in a single lift by the blasting gallery method, Int J Rock Mech \& Min Sci, vol. 41, pp. 45-759, 2004.

[3] A. Jaiswal and B. K. Shrivastva, Numerical simulation of coal pillar strength, Int J Rock Mech Min Sci, vol. 46, No. 4, pp. 779-788, 2009.

[4] J. Zhou, X. Li and H. S. Mitri, Comparative performance of six supervised learning methods for the development of models of hard rock pillar stability prediction model, Nat. Hazard, Vol. 79, No. 1, pp. 291-316, 2015.

[5] S. Peng, On research needs in coal mine ground control, $34^{\text {th }}$ Int Conf on Ground Control in Mining, 2015, available online at: www.icgcm.conferenceacademy.com.

[6] P. R. Sheorey, M. N. Das, D. Barat, R. K. Prasad and B. Singh, Coal pillar strength estimation from failed and stable cases, Int. J. Rock Mech. Min. Sci. \& Geomech. Abstr., Vol. 24, pp.347-355, 1987.

[7] P. R. Sheorey, M. N. Das, S. K. Bordia and Singh B, Pillar strength approaches based on a new criterion for coal seams, Int. J. Min. Geo. Eng., Vol. 4, pp. 273-290, 1986.

[8] P. R. Sheorey, Design of coal pillar arrays and chain pillars, Comprehensive Rock Engineering (Ed. J. A. Hudson et al), Pergamon, Oxford, Vol. 2, pp. 631-670, 1993.

[9] P. R. Sheorey, Experience with the application of modern rock mass classifications in coal mine roadways, Comprehensive Rock Engineering (Ed. J. A. Hudson et al), Pergamon, Oxford, Vol. 5, pp. 411-431, 1993.

[10] P. R. Sheorey, Empirical rock failure criteria, Balkema, Rotterdam, 1997.

[11] P. R. Sheorey, Ground control in bord and pillar mining, A Golden Jubilee Monograph, published by Central Mining Research Institute, Dhanbad, India, 2008.

[12] M. N. Bagde and V. Petros, Fatigue properties of intact sandstone samples subjected to dynamic uniaxial cyclical loading. Int. J. Rock Mech. Min. Sci., Vol. 42, pp. 237-250, 2005.

[13] M. N. Bagde and V. Petros, Waveform effect on fatigue properties of intact sandstone in cyclic loading, Rock Mech Rock Eng, Vol. 38, No. 3, pp. 169-196, 2005.

[14] M. N. Bagde and V. Petros, The effect of machine behaviour and mechanical properties of intact sandstone under static and dynamic uniaxial cyclic loading, Rock Mech Rock Eng, Vol. 38, No. 1, pp.5967, 2005.

[15] M. N. Bagde and V. Petros, Fatigue and dynamic energy behaviour of rock subjected to cyclical loading, Int. J. Rock Mech. Min. Sci., Vol. 46, No. 1, pp. 200-209, 2009.

[16] M. N. Bagde and V. Petros, The effect of microstructure on fatigue behavior of intact sandstone, Int. J. of Geosciences, Vol. 2, No.3, pp. 240-247, 2011. Doi: 10.4236/ijg2011.23026.

[17] L. Tutluoglu, I. F. Oge and C. Karpuz, Relationship between prefailure and post-failure mechanical properties of rock material of different origin, Rock Mech Rock Eng, Vol. 48, pp.121-141, 2015.

[18] J. A. Hudson and J. P. Harrison, Engineering rock mechanics: an introduction to the principles, $1^{\text {st }}$ edn. Pergamon, an imprint of Elsevier Science, Oxford., 1997.

[19] J. J. Crowder and W. F. Bawden, A review of post-peak parameters and behaviour of rock masses: current trends and research, RocNews, Fall 2004, available on line at: http://www.rocscience.com/library/rocnews/Fall2004.htm.

[20] W. R. Wawersik and W. F. Brace, Post-failure behaviour of a granite and diabase, Rock Mech, Vol. 3, pp. 61-85, 1971.

[21] H. Shimizu, T. Koyama, T. Ishida, M. Chijimatsu, T. Fujita and S. Nakama, Distinct element analysis for Class II behaviour of rocks under uniaxial compression, Int J Rock Mech \& Min Sci, Vol. 47, pp. 323-333, 2010.

[22] J. A. Hudson, E. T. Brown and C. Fairhust, Optimizing the control of rock failure in servo-controlled laboratory test, Rock Mech, Vol. 3, pp.217-24, 1971.

[23] W. R. Wawersik and C. A. Fairhurst, Study of brittle rock fracture in laboratory compression experiments, Int J Rock Mech Min Sci, Vol. 7, No. 5, pp. 561-75, 1970.
[24] J. A. Hudson, S. L. Crouch and C. Fairhust, Soft, stiff and servocontrolled testing machines: a review with reference to rock failure, Eng Geol, Vol. 6, pp.155-89, 1972.

[25] K. Xia, Split Hopkinson Pressure Bar (SHPB) tests on Rocks, ISRM News Jr., December, Vol. 12, pp. 72-75, 2009.

[26] X. Li, Z. Zhou, L. Hong, T. Yin and F. Gong, Large diameter SHPB tests with a special striker bar, ISRM News Jr., December, Vol. 12, pp. 76-79, 2009.

[27] J. Zhao and H. B. Li, Experimental determination of dynamic tensile properties of a granite, Int. J. Rock Mech Min Sci, Vol. 37, pp. 861$866,2000$.

[28] X. B. Li, T. S. Lok and J. Zhao, Dynamic characteristics of granite subjected to intermediate loading rate, Rock Mech Rock Engng, Vol. 38, pp. 21-39, 2005.

[29] R. R. Osgoui and E. Unal, An empirical method for design of grouted bolts in rock tunnels based on the Geological Strength Index (GSI), Eng. Geology, Vol. 107, pp. 154-166, 2009.

[30] D. R. Tesarik, J. B. Seymour and T. R. Yanske, Post-failure behaviour of two mine pillars confined with backfill, Int J Rock Mech \& Min Sci, Vol. 40, pp. 221-232, 2003.

[31] van der N. Merwe, 2009, The Challenges of Mining Old, Shallow, Small Coal Pillars, ISRM Newsletter, No. 8, pp.1-5, December 2009.

[32] S. P. Shah, S. E. Swartz and C. Ouyang, Fracture mechanics of concrete: Applications of fracture mechanics to concrete, rock, and other quasi-brittle materials, John Wiley and Sons, Inc. Publication, 1995.

[33] D. G. F. Hedley, Rockburst Handbook for Ontario hardrock mines. CANMET, Energy, Mines and Resources. Canada, Ottawa, 1992.

[34] H. S. Mitri and M. C. Betournay, Progressive failure of norite rock under biaxial loading conditions, CIM Bulletin, Vol. 99, No. 1097, pp. 206-211, 2006.

[35] U. Prasad, Dynamic fracture characteristics of selected rocks. Ph. D. Thesis, Dept. of Mining and Metallurgical Eng., McGill University, Montreal, Canada, May 2000.

[36] C. D. Martin and B. Stimpson, The effect of sample disturbance on laboratory properties of Lac du Bonnet granite, Can. Geotech, Vol. 31, pp.692-702, 1994.

[37] N. Li, P. Zhang, Y. Chen and G. Swoboda, Fatigue properties and a fatigue damage model for jointed rock masses subjected to dynamic cyclical loading, Int J Rock Mech Min Sci, Vol. 40, pp. 145-150, 2003.

[38] B. C. Haimson, Effect of cyclic loading on rock, Dynamic geotechnical testing, ASTM STP 654, American Soc. for Testing and Materials, pp. 228-245, 1978.

[39] V. Petros, M. N. Bagde, K. Holub and P. Michalcik, Comparison of changes in the strength and the deformation behaviour of rocks under static and dynamic loading, $10^{\text {th }}$ congress of ISRM- Technology Roadmap for Rock Mechanics, Vol 2, 8-12 Sept., Johannesburg, South Africa, M. Handely and Dick Stacey (Technical Coordinators), The South African Mining and Metallurgy, pp. 899-902, 2003.

[40] C. D. Martin and N. A. Chandler, The progressive fracture of Lac du Bonnet granite, Int J Rock Mech Min Sci \& Geomech Abstr, Vol. 31, No. 6, pp. 643-659, 1994.

[41] A. N. Stavrogin and B. G. Tarasov, Experimental physics and rock mechanics, Balkema, 2001.

[42] N. Barton and Z. T. Bieniawski, RMR and Q- setting records, Tunnels and Tunnelling International, February, 26-29, 2008 